\title{
EL COTO DE CASASOÁ (MACEDA, OURENSE) EN LA EDAD MEDIA: ESTUDIO Y COLECCIÓN DOCUMENTAL*
}

\author{
Francisco JaVier PÉREZ RodríGuez \\ Instituto de Estudios Gallegos Padre Sarmiento \\ (CSIC-Xunta de Galicia) \\ ORCID iD: http://orcid.org/0000-0002-1600-3084
}

\begin{abstract}
* Este trabajo se enmarca en el proyecto La casa señorial en Galicia (siglos XIII-XVI). Materiales para su estudio, del Programa Estatal de Fomento de la Investigación Científica y Técnica de Excelencia - Subprograma Estatal de Generación del Conocimiento (HAR2017-82480P), del que es investigador principal Pablo S. Otero Piñeyro Maseda.
\end{abstract}

Copyright: (C) 2021 CSIC. La edición electrónica de esta revista se distribuye bajo los términos de una licencia de uso y distribución Creative Commons Reconocimiento 4.0 Internacional (CC BY 4.0).

Cómo citar/Citation: Francisco Javier Pérez RodríGuEz, "El coto de Casasoá (Maceda, Ourense) en la Edad Media: estudio y colección documental", Cuadernos de Estudios Gallegos, 68, núm. 134 (2021), págs. 157-186, https://doi.org/10.3989/ceg.2021.134.05 


\title{
EL COTO DE CASASOÁ (MACEDA, OURENSE) EN LA EDAD MEDIA: ESTUDIO Y COLECCIÓN DOCUMENTAL
}

\section{RESUMEN}

Se editan los tres pergaminos medievales que forman parte del archivo familiar correspondiente al pazo de Casasoá (Santiago de Zorelle, Maceda, Ourense). La publicación de esta documentación inédita se aprovecha para elaborar la historia medieval de un señorío de pequeñas dimensiones que, nacido en la edad media, logrará pervivir hasta la edad contemporánea. PALABRAS ClAVE: archivo familiar, señorío, Galicia.

\section{O COUTO DE CASASOÁ (MACEDA, OURENSE) NA IDADE MEDIA: ESTUDO E COLECCIÓN DOCUMENTAL}

\section{RESUMO}

Edítanse os tres pergameos medievais que forman parte do arquivo familiar correspondente ao pazo de Casasoá (Santiago de Zorelle, Maceda, Ourense). A publicación desta documentación inédita aprovéitase para elaborar a historia medieval dun señorío de pequenas dimensións que, nacido na Idade media, logrará sobrevivir ata a Idade Contemporánea.

PALABRAS ClaVE: arquivo familiar, señorío, Galicia.

\section{THE CASASOÁ COTO (MACEDA, OURENSE) DURING THE MIDDLE AGES: STUDY AND DOCUMENT COLLECTION}

\begin{abstract}
Publication of the three medieval scrolls that are part of the family archive corresponding to the Pazo of Casasoá (Santiago de Zorelle, Maceda, Ourense). The publication of this unreleased documentation is used to write the medieval history of a small-scale manor that is born in the Middle Ages and is able to survive until the Modern Age.

KEY WORDS: family archive, manor, Galicia.
\end{abstract}


Recibido/Received: 28/05/2020

Aceptado/Accepted: 15/11/2020

diferencia de los archivos históricos de titularidad pública, los familia-
res no han sido siempre de fácil acceso. En este ámbito privado existen,
además, enormes diferencias entre los grandes archivos y los pequeños. No cabe duda de que los pertenecientes a las grandes instituciones eclesiásticas, como los catedralicios o los de algún monasterio que consiguió conservarlo tras su ajetreada historia y, en especial, tras la desamortización del siglo XIX, son y han sido siempre bien conocidos, como también los correspondientes a grandes casas nobles, como los ducales de Alba, Medinaceli o Medina Sidonia. Otra cosa, muy diferente, es el de los correspondientes a casas más modestas que permanecen restringidos al ámbito familiar, plenamente privado, cuya existencia es completamente desconocida para quienes se dedican a la historia.

En el caso gallego es especialmente importante llegar, y dar, a conocer, la documentación que se conserva en estos archivos familiares que, no por ser a menudo humildes en cantidad, dejan de tener su importancia. Más aún cuando, como en el caso que aquí se trata, la documentación que aportan corresponde a un ámbito laico, desvinculado de las instituciones eclesiásticas cuyos diplomas han servido mayoritariamente como base para elaborar la historia medieval del reino de Galicia ${ }^{1}$.

\footnotetext{
${ }^{1}$ Son muchos los fondos documentales editados procedentes de archivos eclesiásticos gallegos. Así, por ejemplo cabe destacar que Oseira, Celanova o Santo Estevo de Ribas de Sil tienen prácticamente editada la totalidad de sus colecciones documentales medievales: Miguel Romaní MARTínEZ, A colección diplomática do mosteiro cisterciense de San María de Oseira (Ourense) (1025-1310), Santiago de Compostela, Tórculo Edicións, 1989; Miguel Romaní Martínez, María José Portela Silva, María Pilar RodríGUEZ SuÁrez, y Mercedes VÁzQUEz Bertomeu, Colección diplomática do mosteiro cisterciense de Santa María de Oseira (Ourense), 1310-1399. vol. 3, Santiago de Compostela, Departamento de Historia I, 1993; Miguel Romaní Martínez, M., Pablo S. Otero Piñeyro Maseda, y Margarita Garrido, Colección diplomática do mosteiro cisterciense de Santa María de Oseira (Ourense), 1400-1435, Vol. 4, Santiago de Compostela, Tórculo Edicións, 2003; y Pablo S. Otero PiñEYro MasedA, Colección diplomática do mosteiro cisterciense de Santa María de Oseira (Ourense), 1435-1485, vol. V, Santiago de Compostela, Tórculo Edicións, 2008; Emilio Duro PeÑa, El monasterio de San Esteban de Ribas de Sil, Ourense, Diputación Provincial, 1977; Paula Bouzas Rosende, Documentos galegos do mosteiro de Santo Estevo de Ribas de Sil (século XV), Santiago de Compostela, Consello da Cultura Galega, 2016; José Miguel Andrade Cernadas, O Tombo de Celanova, Santiago de Compostela, Consello da Cultura Galega, 1994, 2 tomos; María Beatriz VaQuero DíAz, Colección diplomática do mosteiro de San Salvador de Celanova (ss. XIII-XV), Vigo, Concello de Celanova; Universidade de Vigo, 2004.
} 
Así pues, como hace unos años manifestaba Pablo S. Otero, "las colecciones documentales no deberían ceñirse únicamente a instituciones monacales o catedralicias, tumbos o códices de referencia, sino también a los archivos pacegos o señoriales", si bien recordaba que "siempre es difícil acceder a los fondos de un archivo privado" 2 . Y es que en buena medida ese es el problema: su acceso y, lo que es evidente para ello, un previo conocimiento de su existencia.

Por suerte, ciertas personas, o familias, propietarias de fondos medievales han puesto a disposición de historiadores e historiadoras, e incluso del público en general, sus archivos. Es, por ejemplo, el caso de los dueños de la torre de Candaira, en cuya página web publican 27 pergaminos, de los cuales una veintena medievales, acompañado alguno de ellos por su transcripción ${ }^{3}$, o los de la casa de Otero, que permitieron estudiar y publicar su documetación al citado Pablo S. Otero ${ }^{4}$. Hay, por último, que recordar los que han pasado a formar parte, por compra, depósito o donación, de los archivos públicos ${ }^{5}$.

\section{El ARCHIVO DEL PAZO DE CASASOÁ}

Por lo dicho, y antes de comenzar propiamente el estudio, quiero manifestar mi agradecimiento a la familia López-Armada Ferreiro, dueña del pazo de Casasoá, por haber puesto a mi disposición su archivo así como el permiso de darlo a conocer.

La colección es pequeña: apenas tres pergaminos, todos ellos del siglo XV. Una humildad que se compensa con el interés que presentan puesto que, salvo la venta de 1490, los otros dos son relativamente atípicos. El primero es el vencimiento del plazo de una deuda, que se salda en 1454 entregando la mitad de la pousa de Casasoá con sus bienes adjuntos y el señorío anexo. Más raro aún es el tercero, donde se reparten las rentas del lugar de Casasoá entre el canónigo Juan Arias y sus tres cuñados en 1498. Que un canónigo sea titular de parte del lugar y su señorío nada tiene que ver con la institución catedralicia a la que pertenece, pues don Juan actúa privadamente, al margen de su condición eclesiástica y de ser miembro del cabildo auriense ${ }^{6}$.

\footnotetext{
2 Pablo S. Otero Piñeyro Maseda, Colección documental del Archivo de la Casa de Otero de Quiroga (Siglos XIII-XVIII), Lugo, Diputación provincial, 2007, pág. 22.

3 Torre-fuerte de la Candaira [en línea], disponible en < http://www.candaira.es/> [Consulta: 11/04/2020].

${ }^{4}$ Pablo S. Otero Piñeyro Maseda, Colección documental del Archivo...

5 Por poner un ejemplo, el de la Casa da Veiguiña, depositado hace unos años en el Archivo Histórico Provincial de Lugo y catalogado por G. Quiroga (Gabriel Quiroga BARrio, A casa da Veiguiña: Descrición do fondo documental, Santiago de Compostela, Consellería de Cultura e Turismo; Arquivo Histórico Provincial de Lugo, 2018).

${ }^{6}$ Como lo pone de manifiesto de forma indudable en la partija: ...renunçio otro qual quer remedio $e$ exseiçon que en contrario desto posa dezer e alegar por razon de miña clerezia, porque quero que me non valla... (doc. núm. 2).
} 
Estos tres pergaminos son capitales para hacer la historia de Casasoá y de su coto, que se extiende exclusivamente por este lugar de la feligresía de Santiago de Zorelle, en el actual término municipal de Maceda, provincia de Ourense. Estamos, pues, lejos de las grandes demarcaciones señoriales propias de la aristocracia, tanto laica como eclesiástica, que abarcan una o más parroquias, al estilo de los cotos catedralicios y monásticos o de los que, incluidos en los alfoces villanos, acabaron en manos de la nobleza titulada.

Una realidad indudablemente más humilde pero no por ello menos expresiva, pues cotos de las dimensiones de Casasoá fueron muy comunes en la Galicia del Antiguo Régimen. De hecho, los siempre mejor documentados y, por ello, estudiados monasterios gallegos ofrecen ejemplos similares al coto que protagoniza este trabajo: frente a los vetustos cotos de Samos o Celanova y los más recientes de los cistercienses Meira o Melón ${ }^{7}$, el benedictino San Pedro de Angoares o las casas femeninas de Cangas y Moreira apenas alcanzarían a los propios edificios monásticos y sus alrededores ${ }^{8}$.

Casasoá es, por tanto, un magnífico ejemplo para contemplar, en la medida de lo que la documentación nos permite, la evolución de un señorío de pequeñas dimensiones que, formado en la Edad Media, logrará permanecer como coto independiente en manos de una familia ajena a la alta aristocracia, pues sus titulares no llegarán a ostentar título alguno9.

\footnotetext{
7 Una aproximación a la diferencia existente entre los cotos monásticos del reino gallego en la Edad Media en Francisco Javier PÉREz RodRíGuez, "Monjes, poder y política", en José Miguel Andrade Cernadas (coord.), El protagonismo monástico a través de la Historia, A Coruña, Hércules de Ediciones, 2016, págs. 162-172.

${ }^{8}$ Ninguno de los tres posee la correspondiente carta de coto, aunque es muy probable que lo hayan tenido, como digo, alrededor del propio monasterio. En Angoares debe haberse transformado en el privilegio de veinte excusados que tiene en el siglo XIII (Ernesto Iglesias AlmeIDA, "El monasterio de San Pedro de Angoares", Soberosum. Revista de Estudios Museo Municipal de Ponteareas, 1 (1993), pág. 119 y doc. núm. 7); en Moreira consta su exención de pechos reales a partir de 1317, y es posible que gozase de coto desde su fundación en 1183, demostrándolo indirectamente que aún en el XVIII el señorío de la parroquia de Santa María de Moreira estuviese compartido entre el conde de Lemos — señor de la jurisdicción de Adai, a la que pertenece la feligresía - y el abad de Meira - heredero del monasterio femenino medieval- (Antonio Martínez Coello, "Santa María de Moreira”, en Damián Yáñez Neira (coord.), Monasticón cisterciense gallego, tomo II, León, Caixavigo e Ourense-Edilesa, 2000, pág. 269; y Francisco Javier Río BARJa, Cartografia Xurisdiccional de Galicia no século XVIII, Santiago de Compostela, Consello da Cultura Galega, 1990, pág. 112). Nada se sabe de Santiago de Cangas, aunque considero muy probable que tuviese un coto similar a los comentados.

9 A mediados del siglo XVIII es su señor Juan Manuel de Prado y Arenillas, vecino de Ourense; tenía por entonces el coto 18 vecinos (Olga GaLlego Domínguez, La organización administrativa territorial de la antigua provincia de Ourense a mediados del siglo XVIII, Ourense, Museo Arqueolóxico Provincial, 1988 (Boletín Auriense, anexo 10), págs. 155-156).
} 


\section{CASAsoÁ, COTO SEÑORIAL EN EL SIGLO XIII}

Casasoá, en la documentación disponible, aparece en la historia en 1204, cuando doña Aldara Fernández, mujer de don Vasco Pérez, lega al cabildo de Ourense dos casales, junto a otro en el próximo lugar de Calvelo, también en la feligresía de Zorelle, para que, de sus rentas, se asignen diez sueldos anuales para celebrar un aniversario el día de la Purificación de la Virgen ${ }^{10}$. Dos años después, la dueña cambiaba el destino de estos casales: mientras que el de Calvelo seguía legándolo al cabildo auriense, los dos de Casasoá pasarían a Arias Fernández, quien podría escoger entre ellos y otras heredades, pasando -de elegir estas últimas- a poder de los canónigos ${ }^{11}$.

El testamento de doña Aldara - que tiene hasta tres redacciones, una por año, en 1204, 1205 y 1206- muestra que su patrimonio se centra en la tierra de Caldelas, extendiéndose a las de Penafiel, Aguiar y la ciudad de Ourense y, aunque parece querer enterrarse en ésta -no lo expresa directamente-, sus mandas la muestran devota de los monasterios de esas comarcas más la de Trives, pues hace legados a los de Santa María de Montederramo, San Paio de Abeleda, San Clodio de Ribas de Sil, los hospitalarios de San Lourenzo de Ribas de Sil -o Barxacova-, Santa Cristina de Ribas de Sil, San Pedro de Rocas y San Salvador de Sobrado de Trives.

Pocos años después Casasoá aparece unido a Santa María de Don Franque, Almoite y un casal en Guamil al reclamar la propiedad del conjunto el monasterio de Santo Estevo de Ribas de Sil. El 8 de diciembre de 1213 Alfonso IX, previa pesquisa en la zona, entregaba al cenobio la posesión de lo reclamado por abad y monjes ${ }^{12}$, sin que se diga quién o quiénes le negaban su dominio.

Los mismos bienes aparecen juntos, unidos a otros, veinte años después, en 1233, cuando el monasterio de Santo Estevo suscribe un acuerdo con don Pelayo Arias y su mujer, doña María Rodríguez, mediante el cual el cenobio cede al matrimonio la mitad de todas las heredades propias del monasterio que éste tiene, o por derecho pueda recuperar, en Santa María de Don Franque, en Ca-

\footnotetext{
${ }^{10}$ María Beatriz Vaquero DíAz y Francisco Javier Pérez Rodríguez, Colección documental del Archivo de la Catedral de Ourense, I (888-1230), León, Centro de Estudios e Investigación San Isidoro; Caja España de Inversiones; Archivo Histórico Diocesano, 2010 (Colección Fuentes y Estudios de Historia Leonesa, 131), pág. 231 (doc. núm. 99).

${ }^{11}$...Arie Fernandi duo casalia de [C]asasua tali conditione quod si ipse ire uoluerit ad alias hereditates, scilicet, de Pedron et de Vilar et de Caluilu, canonici recipiant totam hereditatem quam habeo in Casasua... [VAquero Díaz y Pérez Rodríguez, Colección documental del Archivo..., pág. 241 (doc. núm. 106)].

${ }^{12}$ Duro PeÑa, El monasterio de San Esteban de Ribas de Sil, págs. 255-256 (doc. núm. 10). Santa María de Don Franque es hoy una ermita en la parroquia de San Pedro de Maceda (Maceda), mientras que Almoite y Guamil son lugares de las feligresías de sus mismos nombres, ambas bajo la advocación de Santa María, en el ayt. ${ }^{o}$ de Baños de Molgas.
} 
sasoá, en Almoite, en Guamil, en San Xiao, en Dúas Igrexas, en Merí, en tierra de Penafiel y en toda la tierra de Xunqueira y de San Xoán, salvo San Román y Sobradelo, con toda su derechura, y el casal que tiene don Fernando Méndez en San Paio de Merí. Don Pelayo devuelve a Santo Estevo las heredades que le pertenecían en esos lugares, salvo en sus cotos propios de Maceda y Bustavalle, y se añade el compromiso de que todo lo que en ellos trabajen los monjes, o sus hombres, con sus bueyes, el monasterio se quedará con dos tercios de lo producido, repartiéndose el tercio restante a medias entre él y don Pelayo, salvo de sachado, de lo que el aristócrata recibirá solamente la mitad de un cuarto. Al fallecer ambos cónyuges todo volverá a Ribas de Sil, incluida esa renta de la mitad del tercio de lo cosechado ${ }^{13}$.

Mientras que Don Franque pasa a poder de Santo Estevo, que lo afora en $1234^{14}$, nada vuelve a saberse de Casasoá hasta el siglo XV. Por lo visto, a principios del XIII su propiedad estaba repartida entre el monasterio y, al menos, doña Aldara Fernández, que disponía de dos casales, si bien puede ser que ambos estuviesen entre los bienes reclamados por abad y monasterio en 1213. Doña Aldara es muy probablemente pariente del don Pelayo Arias que suscribe el acuerdo con Ribas de Sil en 1233.

Se trata de don Pelayo Arias de Ambía, a quien documento por primera vez en 1219 suscribiendo un acuerdo con don Lorenzo, obispo de Ourense, sobre bienes en Soutomaior, A Mezquita, Ambía - que dona al prelado-, Coucieiro, Bustavalle y Vilarellos, que recibe del obispo en prestimonio vitalicio ${ }^{15}$, mostrando así sus intereses en la tierra de Penafiel $^{16}$, en donde tiene los coutos de

13 Duro Peña, El monasterio de San Esteban de Ribas de Sil, págs. 273-274 (doc. núm. 34).

14 Duro Peña, El monasterio de San Esteban de Ribas de Sil, págs. 276 (doc. núm. 37).

15 Vaquero Díaz y Pérez Rodríguez, Colección documental del Archivo..., págs. 288-290 (doc. núm. 142). Santiago de Soutomaior (Taboadela), San Pedro da Mezquita (A Merca) y Coucieiro (San Vicenzo de Coucieiro, Paderne de Allariz) entre Ourense y Allariz, mientras que los lugares restantes se encuadran, en la tierra de Ambía-Molgas, Ambía, en la parroquia de su nombre — Santo Estevo de Ambía-o próxima - Santa María de Ponte Ambía_, y, en la de Penafiel, los lugares de Bustaballe y Vilarellos, ambos en la feligresía de Santiago de Zorelle - junto a Casasoá- (Maceda).

${ }^{16}$ Muy mal documentada, esta tierra de Penafiel — que tal vez deba identificarse con la de Molgas - se extendería por la margen derecha del río de Maceda, ocupando parte de los actuales términos municipales de Xunqueira de Espadanedo, Maceda, Paderne de Allariz y Baños de Molgas. Su primer tenente conocido es Vasco Méndez — quizás el abuelo del don Pelayo Arias que aquí tratamos-, que lo era en 1174, cuando hace una gran donación a Montederramo en la dice tener por este monasterio la villa de Coucieiro, la misma que entrega don Pelayo al obispo de Ourense en 1219 (Ramón LoREnzo, Colección documental do mosteiro de Montederramo, tomo 1, Santiago de Compostela, Consello da Cultura Galega, 2016, págs. 209-210 (doc. núm. 24). En 1369 fue dada en señorío, entre muchas otras, a don Juan Rodríguez de Biedma por Enrique II (José García Oro, y María José Portela Silva, O condado de Monterrei no século XVI. Estudo histórico e colección diplomática, Noia, Grupo Filatélico e Numismático de Noia, 2003, pág. 21). Su centro estaría en el castillo de Maceda. 
Bustavalle y Maceda pro sua hereditate ${ }^{17}$. Don Pelayo Arias sería la segunda generación que une al patronímico el nombre de la comarca de donde era originaria la familia ${ }^{18}$. Los primeros en hacerlo habrían sido quienes deben ser su padre y su tío: don Arias y don Pelayo Vázquez de Ambía, que en 1196 confirman el acuerdo que suscriben Santo Estevo de Ribas de Sil y el tenente de la tierra de Temes bajo autorización de Alfonso IX ${ }^{19}$.

Este mismo monarca se dirigía a él, a don Pelayo, en fecha indeterminada, para prohibirle que entrase en el coto de San Pedro de Rocas por heredad realenga ni a voz de la tierra por la voz de Molgas, pues tenía privilegio desde tiempos de Alfonso VII ${ }^{20}$. La orden debe haber sido dada hacia 1226, cuando el caballero aparece como tenente Amolgas ${ }^{21}$.

Como toda su familia, don Pelayo debe haber servido al más destacado linaje de los Limia, como lo demuestra que, entre 1231 y 1245, aparezca regularmente junto a don Fernando Eanes Batisela, ricohombre de la corte de Fernando III ${ }^{22}$, al frente de la tenencia de Limia $^{23}$. Mientras Batisela estaría regularmente junto al monarca, don Pelayo sería quien estuviese presente en el territorio, como lo de-

\footnotetext{
17 Similiter de quanto recuperare sive obtinere potuerint per iudicium in cauto de Maceeda et in cauto de Bustavali, quos domnus Pelagius tenet pro sua hereditate... (Duro PeÑA, El monasterio de San Esteban de Ribas de Sil, pág. 274 (doc. núm. 34).

18 Sobre esta familia, Pablo S. Otero Piñeyro Maseda, "Apuntes de los Ambía: linaje y parentelas (siglos XII-XVI)”, Cuadernos de Estudios Gallegos, 56 (2009), págs. 445-457, y Eduardo PARDO DE GuEVARA Y VALDÉS, De linajes, parentelas y grupos de poder. Aportaciones a la historia social de la nobleza bajomedieval gallega, Madrid, Fundación Cultural de la Nobleza Española, 2012, pág. 296 núm. 41.

19 Duro Peña, El monasterio de San Esteban de Ribas de Sil, pág. 253 (doc. núm. 7).

${ }^{20}$ Emilio Duro Peña, El monasterio de San Pedro de Rocas y su Colección Documental, Ourense, Diputación Provincial, 1972, pág. 141 (doc. núm. 10). Esta mención a la voz de Molgas insiste en la relación de don Pelayo con la zona, pues Molgas se encuentra no muy lejos, río arriba, de las parroquias que todavía llevan el nombre de Ambía; todas ellas pertenecen al actual término municipal de Baños de Molgas. ${ }^{21}$ Lorenzo, Colección documental..., pág. 263 (doc. núm. 82).

${ }^{22}$ No es éste lugar para extenderse sobre los Limia, que cuentan con una bibliografía relativamente amplia. Remito a José Agusto SotTomaYor-Pizarro, "Os Limas: da Galiza a Giela (séc. XII a XVI)", en Casa Nobre. Um património para o futuro. 2 . $^{\circ}$ Congresso Internacional. Actas, Arcos de Valdevez, Municipio de Arcos de Valdevez, 2011, págs. 53-74, e Inés CALDERón MedinA, Cum Magnatibus regni mei. La nobleza y la monarquía leonesas durante los reinados de Fernando II y Alfonso IX (1157-1230), Madrid, Consejo Superior de Investigaciones Científicas, 2011 (Biblioteca de Historia, 74).

${ }^{23}$ Sus nombres suelen aparecer juntos al frente de la tenencia de Limia, aunque también hay ocasiones en el que lo hace solamente uno de los dos (AHN, Clero, Melón, Carp. 1441, núms. 3, 9 y 13; Duro PeÑA, El monasterio de San Esteban de Ribas de Sil, págs. 270, 275, 276; Manuel LuCAs Álvarez, y Pedro Pablo Lucas Domínguez, San Pedro de Ramirás. Un monasterio femenino en la Edad Media. Colección diplomática, Santiago de Compostela, Caixa Galicia, 1988, págs. 196, 200; José MARQuES, O cartulário do mosteiro de Fiães, Melgaço, Câmara Municipal de Melgaço, 2016, págs. 151, 216, 218-222, 225, 227, 228, 231, 263; Romaní MARTínez, A colección diplomática do mosteiro cisterciense..., págs. 339, 449, 516; Miguel Romaní Martínez, y Pablo S. Otero Piñeyro Maseda, "Documentación del fondo de Oseira (AHN) relacionada con el monasterio de San Pedro de Vilanova de Dozón (1015-1295)", Cuadernos de Estudios Gallegos, 116 (2003), pág. 58; VAQuero DíAZ, Colección diplomática do mosteiro de San Salvador..., págs. 83-88).
} 
mostraría que aparezca, en solitario, al frente de la tierra de Aguiar de Pedraio ${ }^{24}$, el castillo de Aguiar da $\mathrm{Moa}^{25}$ y la villa y fortaleza de Allariz ${ }^{26}$.

Volviendo a Casasoá, en 1223 todavía no parece conformar un coto, a diferencia de Bustavalle, en la misma parroquia, que ya lo es entonces. Cabe suponer que se convirtió en señorío en algún momento del siglo XIII, cuando Alfonso IX, o ya Fernando III, más difícilmente Alfonso X, concediéndosele al mismo don Pelayo Arias de Ambía o a alguno de sus herederos.

\section{CASASOÁ Y SUS SEÑORES EN EL SIGLO XV}

Casasoá reaparece en la documentación a mediados del XV, ya en el archivo privado de su pazo. En 1454 se cede a nosa pousa e lugares de Casasoaa con todas súas casas e herdades e cortinas e áruores e pascos e montesíos e ágoas vertentes e correntes e manantes, e foros, seruiços, dereitos e dereituras e cousas a a dita pousa e lugares perteeçentes e perteeçer deuentes así de feito como de dereito ${ }^{27}$. La pousa es un centro que vertebra un dominio fundiario y señorial que puede asociarse, en la documentación monástica, al término más conocido de granja. A ella acudirían a entregar las rentas los foreros y arrendadores de las tierras del dominio así como los couteiros de las que deban en razón de señorío ${ }^{28}$. Que estamos ante éste, es decir, que Casasoá es indudablemente un coto, se pone de manifiesto en la donación, pues los bienes van acompañados con toda a voz e avçón, dereito e jurdiçón tenporal, e justiçia e senorío real, çebil e criminal. Sus dueños tienen derecho, pues y en principio, a poner juez, merino y notario en el lugar, así como de recibir las rentas que pagan en concepto de señorío sus habitantes.

\footnotetext{
24 Marques, O cartulário do mosteiro de Fiães..., págs. 210-215, 217-220.

25 Duro PeÑa, El monasterio de San Esteban de Ribas de Sil, págs. 273, 277; Romaní Martínez, A colección diplomática do mosteiro cisterciense..., págs. 339, 357.

${ }^{26}$ Pedro Dono LóPez, Colección de documentos en pergamiño do mosteiro de Santa Comba de Naves. Introdución, edición e índices, Tesis doctoral inédita, Santiago de Compostela, Universidade de Santiago de Compostela, 2010, pág. 150; Emilio Duro PeÑa, "El monasterio de Santa Marina de Asadur", Archivos Leoneses, 27 (1973), pág. 332; Adolfo Fernández Fernández, O mosteiro feminino de San Miguel de Bóveda na Idade Media. Estudio histórico e colección documental (séculos XII-XV), Noia, Toxosoutos, 2005 (Trivium, 17), pág. 128; Ana M. Gordín VeleIro y Luisa de la Ascensión PeÑA PéRez, O mosteiro de Santa María de Xunqueira de Espadanedo nos séculos XII-XVI, Ourense, Deputación de Ourense, 2019, págs. 81-82; Lucas Álvarez y Lucas Domínguez, San Pedro de Ramirás..., pág. 198; Marques, O cartulário do mosteiro de Fiães..., págs. 210; Romaní MARTíneZ, A colección diplomática do mosteiro cisterciense..., pág. 458, 467.

27 Documento núm. 1 de los aquí publicados.

${ }^{28}$ Conf. María Beatriz Vaquero Díaz, “A xestión patrimonial do mosteiro de Celanova na Baixa Idade Media”, Semata, 15 (2003), pág. 227.
} 
En el edificio de la pousa se concentrarían, pues, las rentas correspondientes a la explotación de las tierras y al señorío que se reparten sus dueños en $1498^{29}$. Al señorío correspondería la carne, así de porco como de outra qualquier que seja, mientras que a los foros de la tierra respondería todo o pan que afluye a la pousa. Cabe también suponer que ésta sería la antecesora del pazo actual, aunque en él no quede rastro medieval alguno.

En 1454 Casasoá no está ya en poder de una gran familia aristocrática sino en manos de Gonzalo de Sarria y su mujer, Inés Alfonso, vecinos y moradores de la ciudad de Ourense. De no haberla comprado, pousa y coto serían herencia de ella. Gonzalo de Sarria era el segundo marido de Inés Alfonso, que había estado casada antes con el escudero Álvaro Ouxea, también vecino de Ourense.

Éste habría recibido el mismo nombre que su padre, quien se documenta a finales del siglo XIV con su mujer, Constanza Gómez; vecinos y moradores en Ourense, hacia 1394 aforaban al cabildo catedralicio unas casas con lagar en la rúa Nova cerca de la plaza del $\mathrm{Campo}^{30}$. Su apellido los vincula a los Ouxea de Albán, o de Vilamarín ${ }^{31}$, confirmando su pertenencia a la familia que tenga bienes en la parroquia de San Xiao de Ribela, en la ribera derecha del Miño ${ }^{32}$. En 1413 aparece como testigo Álvaro Ougea o Vello ${ }^{33}$, que sería el padre, mientras que en 1424 Álvaro Ougea o Moço, el hijo, está presente a la concesión de un foro que hace Leonor de Nóvoa, viuda de Luis de Vilamarín ${ }^{34}$. Entre ambas fechas debe haber fallecido o Vello ${ }^{35}$, mientras que $O$ Mozo estaba ya muerto en 1435 .

Es en este año cuando doña Inés, moller que foy de Alvaro Ougea, deja que se subaste públicamente, se supone para pagar una deuda con el concejo, huna castana de mar engastada en prata. Vive en la rúa Nova, con seguridad en las

\footnotetext{
29 Doc. núm. 3.

${ }^{30}$ Amalia López Martínez, Minutarios notariales de Estevo Pérez, Tesis doctoral inédita, Ourense, Universidade de Vigo, 2015, págs. 493 y 754-755.

31 Como muchas otras familias hidalgas, los Ouxea carecen de un estudio que los tenga por objeto. Su individuo más conocido es Pedro Ouxea de Albán que, en realidad, son dos, Pablo S. Otero PiÑEYro MASEDA, "Apuntes genealógicos de una estirpe de escuderos gallegos: los Mosquera (siglo XV)", en José Antonio García Luján (ed.), Simposio Nobleza y Monarquía. Los linajes nobiliarios en el reino de Granada. Siglos XV-XIX. El linaje Granada Venegas, marqueses de Campotéjar, Huéscar, Asociación Cultural Raigadas, 2010, págs. 220-226.

32 Anselmo López Carreira, Libro de notas de Álvaro Afonso. Ourense, 1413, Santiago de Compostela, Consello da Cultura Galega, 2005, págs. 31-32 y 129-130.

${ }^{33}$ López Carreira, Libro de notas de Álvaro Afonso..., pág. 194.

${ }_{34}$ Ana María Gordín Veleiro, Minutarios notariais de Rodrigo Afonso, Gonzalo de Baeza e Pedro Sánchez de Baeza (Ourense, siglo XV), Tesis doctoral inédita, Ourense, Universidade de Vigo, 2015, pág. 450 .

${ }^{35}$ En 1419 el cabildo afora una viña que limita con otra que foy de Aluaro Ougea. Por su parte, o Mozo se documenta en 1424 y 1429 (Gordín Veleiro, Minutarios notariais..., págs. 236, 450, 611, 612, 953, 955 у 938).
} 
casas que sus suegros habían aforado al cabildo en 1394, de cuyo pago se está haciendo cargo todavía en 1453. Es entonces cuando, en el registro de bienes que hacen los capitulares, se nos informa de que está casada con Gonzalo de Sarria:

\begin{abstract}
Alvaro Ougea, o Vello. Sua moller, que he moller de Gonçalvo de Sarrea. Iten, por hunas casas de cabo do Canpo çinquoenta marabedis longos, as quaes ten aforadas do cabidoo, que son çinquoeenta et tres marabedis et dous coroados curtos $^{36}$.
\end{abstract}

En cuanto a él, su patronímico obliga a haberlo proceder de la villa de Sarria. Aunque consta una carta de vecindad en Ourense en 1441, lo cierto es que se documenta en la ciudad desde $1413^{37}$, constando ya entonces como su vecino ${ }^{38}$. Ese año el concejo lo condenaba a satisfacer su deuda con Pedro do Tiollo al incumplir el contrato, la aviinça, que con él tenía, sin que se nos diga en qué consistía ${ }^{39}$.

Sin embargo, su presencia en Ourense no se regulariza hasta 1431, prolongándose hasta 1459, año en que desaparece de la documentación. Aunque no forma parte de la elite de la ciudad, no cabe duda de que no es un artesano. De vez en cuando aparece en las reuniones del concejo ${ }^{40}$, y consta que fue arrendador de algunas de sus rentas, como la del portazgo que se cobra por pasar el río $\mathrm{Miño}^{41}$ o la alcavala de sal et bestas en $1458^{42}$, mientras que en 1441 pujó por quedarse con la sisa del pescado que se vendía en la ciudad, por la que ofreció 700 maravedíes y una dobla, perdiéndola al ofrecer Fernando de Verín 200 maravedíes y otra dobla por encima ${ }^{43}$. En 1441 es oficial del concejo, al que sirve como postor,

\footnotetext{
${ }^{36}$ María Beatriz Vaquero Díaz, Libro das posesións do Cabido Catedral de Ourense (1453). Edición, transcrición e índices, Vigo, Universidade de Vigo, 2005, pág. 85. Es de suponer que este Vello es el mozo de 1424-1429, pues no es posible que se trate de su padre, documentado entre 1393 y 1419. De la mención cabe también suponer que hay, en 1453, un tercer Álvaro Ouxea que no parece hijo del segundo y de Inés Alfonso puesto que no es titular del foro de las casas de la rúa Nova.

37 López CARreira, Libro de notas de Álvaro Afonso..., págs. 14, 32-34, 59, 65, 66 y 265.

38 López CARreira, Libro de notas de Álvaro Afonso..., págs. 175 y 253-254.

39 López CARreira, Libro de notas de Álvaro Afonso..., págs. 33-34.

${ }^{40}$ Bien entre los reunidos, bien como testigo de la reunión, o de la factura de documentos, aparece en 1433, 1435, 1439, 1446, 1454, 1457, 1458 y 1459 (Jesús Ferro Couselo, A vida e a fala dos devanceiros: escolma de documentos en galego dos séculos XIII ao XVI, Vigo, Galaxia; Fundación Penzol, 1996 [ed. facs. de la de 1967], págs. 250, 298, 304, 335, 441, 647 y 649; Anselmo López CARreira, Fragmentos de notarios (Ourense, séculos XIV-XVI), Santiago de Compostela, Consello da Cultura Galega, 2007, págs. 72, 147, 190 y 480; María José Losada Meléndez, Libros de notas de Juan de Ramuín (Ourense, siglo $X V$ ), Tesis doctoral inédita, Ourense, Universidade de Vigo, 2015, pág. 64).

${ }^{41}$ Que tuvo por dos años, como declara en noviembre de 1457 (FERro Couselo, A vida e a fala..., págs. 661-662).

42 LÓPEZ CARreira, Fragmentos de notarios..., pág. 112.

${ }^{43}$ La sisa era para realizar la recontrucción de Puente Mayor, hoy Viejo, sobre el Miño (FerRo CousELo, A vida e a fala..., pág. 650).
} 
para repartir la cantidad asignada por el municipio a la calle correspondiente, en 1434,1455 y $1456^{44}$.

Sus negocios no parecen haber ido siempre bien: en 1434, para pagar uno de los pedidos municipales, tuvo que empeñar una sortija que, valorada en 18 maravedíes, contribuiría a pagar los 38 que se le habían asignado ${ }^{45}$, mientras que al año siguiente fueron rematadas en pública subasta duas almadraquejas de Gonçalvo de Sarria, compradas por Alfonso de Betanzos por 20 maravedíes $^{46}$. Vivía por entonces en la rúa dos Zapateiros, de donde, al casarse con Inés Alfonso, se marcharía a la rúa Nova, en la que vive en $1454^{47}$. Llama la atención que, este año y el siguiente, es uno de los vecinos que menos aportan en los repartos al ser gravado con 3 maravedíes, que contrastan con los 21 pagados por el mercader Juan Alfonso o por Ares de Monterroso ${ }^{48}$. Sus negocios lo involucraron en más de un problema con la justicia, como lo prueba que en 1459 fuese detenido en su casa Gómez de Monterroso ${ }^{49}$ o que, años antes, fuese fiador, con otros, de que se sacase de la cárcel a un vecino de Bobadela, lugar al otro lado del Miño ${ }^{50}$. Esto no quita para que actúe, en ocasiones, como procurador de otras personas ante los tribunales de justicia ${ }^{51}$.

Cuando, en 1454, el de Sarria y su mujer donan su pousa y lugar de Casasoá debían tener ya una edad avanzada, como lo demostraría que él desaparezca de la documentación a partir de junio de 1459. La cesión es clara: se hace en agradecimiento y en pago de una deuda que ha servido espeçialmente para noso manteemento e sustentamento de nosa vida e honrra e estado, e para reparar nosa fazenda. La honra e estado remitirían a la condición de ciudadanos de relativa alta posición del matrimonio puesto que, al menos él, no parece haber sido hidalgo.

Los vaivenes de los negocios de Gonzalo de Sarria harían necesaria esta donación, o entrega por impago de deuda, pues las actividades que desarrolla en los años finales de su vida no parecen haber ido muy allá. En 1448 es uno de los

\footnotetext{
${ }^{44}$ Ferro Couselo, A vida e a fala..., págs. 499-500, 692; Anselmo LóPez Carreira, Padróns de Ourense no século XV, Santiago de Compostela, Consello da Cultura Galega, 1995, págs. 62 y 67.

45 López Carreira, Padróns de Ourense..., pág. 37.

${ }^{46}$ López Carreira, Fragmentos de notarios..., pág. 313.

47 López Carreira, Padróns de Ourense..., págs. 58 y 67.

${ }^{48}$ En 1454 a su nivel, con tres maravedíes, están Diego Fernández, Juan Destar, Teresa de Sobrado, Inés González y Aldonza Cansada, yendo por debajo siete mujeres solas y cuatro hombres (LóPEz CARREIRA, Padróns de Ourense..., págs. 57-58).

49 Ferro Couselo, A vida e a fala..., pág. 312; y López Carreira, Fragmentos de notarios..., pág. 110.

${ }^{50}$ López CARreira, Libro de notas de Álvaro Afonso..., pág. 175.

${ }^{51}$ En 1431 es procurador de varios vecinos de la aldea de Cerreda que se enfrentan al monasterio de Ribas de Sil por el cachón do Camilo, y en 1459 Juan Vázquez Garza e Inés de Nóvoa le dan poder para que los represente en el pleito que mantienen con Teresa López (BouZas Rosende, Documentos galegos do mosteiro de Santo Estevo..., págs. 186-194; y López CARREIRA, Fragmentos de notarios..., pág. 186).
} 
orensanos que roban, sin rebozo, los materiales de los baños del Posío, de los que tomó a pechadura ... da porta de dentro ${ }^{52}$. En 1455 su casa fue una de las apedreadas desde el Pazo e Curral do Bispo $^{53}$, y en 1459 está en pleito intentando cobrar ciertas deudas ${ }^{54}$.

Quienes se hacen con Casasoá en 1454 son el platero Pedro Arias y su mujer, Mayor Pereira, también vecinos de Ourense pero que, como Gonzalo de Sarria, tampoco serían originarios de la ciudad. Él aparece por primera vez en Ourense el 29 de abril de 1446, cuando suscribe con el concejo su carta de vecindad, en la que se compromete a pagar anualmente al municipio 15 maravedíes el día de san Martín ${ }^{55}$. Vivía en la rúa Nova, constatando las derramas del concejo que tenía una desahogada posición: gravado con 13 maravedíes -10 más que su vecino Gonzalo de Sarria- entra en el grupo de los de renta media ${ }^{56}$. Su oficio avala esa disponibilidad económica y, aunque consta haber participado como arrendador de las rentas concejiles ${ }^{57}$, parece haberse dedicado -aparte de a su profesión de platero- al préstamo, es de suponer, con interé ${ }^{58}$. La relación con miembros de su profesión de, al menos, Santiago de Compostela se muestra en 1459 cuando el concejo le demanda que, en diez días, traiga a su presencia al platero compostelano Pedro Alfonso para que responda por no haber pagado la alcabala correspondiente a la venta de dos taças que había hecho en la ciudad ${ }^{59}$. Poco más puede decirse de él, salvo que, de nuevo en 1459, era mayordomo de la cofradía de San Miguel ${ }^{60}$.

Curiosamente, después de esa fecha vuelve a saberse de él pero no por sí mismo sino por su mujer: en 1470 , cuando se comprueba que se hayan cumplido

\footnotetext{
${ }^{52}$ Ferro Couselo, $A$ vida e a fala..., pág. 372.

53 Ferro Couselo, $A$ vida e a fala..., pág. 542.

54 López Carreira, Padróns de Ourense..., págs. 117-118.

${ }^{55}$ Ferro Couselo, A vida e a fala..., pág. 412; y Anselmo López Carreira, A cidade de Ourense no século XV. Sociedade urbana na Galicia baixomedieval, Ourense, Deputación Provincial, 1998, pág. 556.

${ }^{56}$ López CArreira, Padróns de Ourense..., págs. 58 y 67.

${ }^{57}$ Consta solamente en 1459, cuando declara que fue él quien se quedó con la alcavala do calles y no el clérigo Juan Fernández y Fernando López, a quienes se la reclamaban el pregonero y nuestro ya conocido Gonzalo de Sarria (López CARreira, Fragmentos de notarios..., pág. 112).

${ }^{58}$ En 1458 presta una dobla al concejo para que se compre el hierro necesario para la obra del Puente Mayor. Al año siguiente consiente en ser aval de Gómez Alfonso, clérigo de Rouzós, al aforar durante cuatro año el beneficio de San Vicenzo de Reádigos, y demanda a Abraham Vello, quien quería embargar varios bienes de la judía Donouro -lo que apunta a ser el platero quien tiene derecho a hacerlo antes-, e incluso la intervención en la alcabala recogida en la nota anterior permite apuntar también al préstamo, aparte de la propia escritura de donación de Casasoá (FERro Couselo, A vida e a fala ..., pág. 667, y LóPEZ CARreira, Fragmentos de notarios..., págs. 134 y 170).

${ }^{59}$ López Carreira, Fragmentos de notarios..., pág. 191.

${ }^{60}$ López CARreira, Fragmentos de notarios..., pág. 173. Esta cofradía agrupaba, en principio, a los herreros, aunque no sería en exclusiva de los oficios relacionados con el hierro (LóPEZ CARREIRA, $A$ cidade de Ourense..., pág. 334).
} 
las mandas testamentarias de Fernando González, clérigo de Santa Marta de Velle, se afirma que Se pagou de pan para dar de comer aos clerigos este dito dia vynte marabedis a Moor Pereira, moller de Pero Ares ${ }^{61}$. Llama la atención que sea a ella, y no a su marido, a quien se haya encargado el pan para la clerical pitanza, pues me parece dudoso que la mujer de un platero sea panadera, con lo que es de suponer que, por especial relación con el difunto o con sus cumplidores testamentarios, haya sido la intermediaria, la encargada del asunto. Sea como fuere, la mención demuestra que tanto ella como su marido estaban todavía vivos $\mathrm{y}$, de rondón, la gran diferencia que en el trato documental reciben mujeres y hombres ${ }^{62}$.

Esta diferencia se pone aún más de relieve en el acuerdo entre los dueños de Casasoá de 1498, número 3 de los que se editan. La reunión es exclusivamente masculina, representando a las hermanas y coherederas del canónigo sus respectivos maridos, sin siquiera molestarse en copiar su nombre. De hecho, solamente conocemos el de una de ellas, María Pérez, al figurar junto al suyo, Juan González Cuadrado o Mozo en la compra del casal de Calvelo en $1490^{63}$. Queda claro, pues, que los herederos de Casasoá son el canónigo Juan Arias y sus tres hermanas, de las que solamente conocemos a María Pérez. Aunque no se exprese, no creo que quepa duda de que se trata del hijo e hijas del platero Pedro Arias y Mayor Pereiras; mientras que el hijo toma directamente el apellido de su padre, las hijas se identifican como hijas de Pedro, Pérez.

Del único varón de la familia poco se puede añadir aparte de su condición de canónigo de la catedral auriense, donde consta haberlo sido desde $1487^{64}$. Cabe destacar que en 1488, con su colega Alfonso Valente, se hacía con la tenencia

\footnotetext{
${ }^{61}$ Losada MelÉndez, Libros de notas de Juan de Ramuín..., pág. 382.

${ }^{62}$ Aunque no cabe duda de que todavía falta mucha documentación inédita por consultar, cabe destacar la gran diferencia que existe entre Gonzalo de Sarria y Perdo Arias a la hora de asomarse a los diplomas. Aún teniendo en cuenta la falta de estos, no cabe duda de que el de Sarria participó de manera más activa en las reuniones concejiles. Del platero, aparte de las referencias dadas, hay apenas que añadir su presencia tres veces más como testigo en sendos documentos, todos ellos de 1459 (López CARREIRA, Fragmentos de notarios..., págs. 88, 111 y 190). Por otra parte, obsérvese que, frente a las menciones de uno y otro, de sus respectivas mujeres solamente se conservan dos para cada una: para Mayor Pereira esta de 1470 y la común con Inés Alfonso en la donación de Casasoá; de ésta la segunda es el remate comentado de su castana de mar engastada en prata, y cabría una tercera en el fragmento copiado más arriba en el que no aparece su nombre sino el de sus dos maridos: Alvaro Ougea, o Vello. Sua moller, que he moller de Gonçalvo de Sarrea...

63 Doc. núm. 2.

${ }^{64}$ Losada Meléndez, Libros de notas de Juan de Ramuín..., pág. 824. No creo que el Juan Ares racionero de Lugo y Ourense que en 1471 renuncia a su ración en esta segunda catedral — precisamente por tal renuncia- deba tratarse del heredero de Casasoá (LosAda Meléndez, Libros de notas de Juan de Ramuín..., pág. 339). López Carreira lo identifica como canónigo en las dos últimas décadas del cuatrocientos (López CARreira, A cidade de Ourense..., pág. 573).
} 
capitular de Mourisco y Paderne, lugares próximos a Casasoá ${ }^{65}$. Haber entrado en el cabildo catedralicio confirma la solvencia económica de sus padres, mientras que las bodas de sus hermanas siguen situando a la familia en esa segunda fila de la élite social del Ourense de la época, como se ha visto en Gonzalo de Sarria y Pedro Arias.

El menos conocido, o documentado, de los tres es Alfonso González Portugués, o simplemente Alfonso Portugués, que figura entre 1487 y 1504 en los padrones de la ciudad publicados por Anselmo López Carreira. Su apodo lo hace nativo del reino de Portugal, y vive en la rúa do Campo o en la das Tendas a lo largo de todo el período, siendo en 1495, 1498 y 1504 uno de los postores de la derrama en esas calles, que tributan juntas ${ }^{66}$.

Juan Bravo tampoco es orensano de nacimiento, pues se trata probablemente del hijo del notario del mismo nombre, familiar del abad de Santa María de Oseira, y de Constanza de Santa María, que vivían en o junto al mismo monasterio cisterciense ${ }^{67}$. Desde 1480 reside en Ourense, en la rúa Nova, tal vez por haberse casado ya con la hija de los señores de Casasoá y convivir en la misma casa; en esa calle reside hasta por lo menos 1504, siendo -como su concuñado-postor de las derramas del concejo en ella en varias ocasiones, siendo su cobrador en 1484 y $1492^{68}$. En el reparto de 1480 paga 18 maravedíes, situándose en el segundo grupo que más paga ${ }^{69}$. Para distinguirlo de su padre homónimo, cuando visita Oseira se le distingue como $O \mathrm{Mozo}^{70}$.

Frente a los anteriores, el tercer yerno de los señores de Casasoá era oriundo de Ourense, de una familia de zapateros documentada en la ciudad desde los años veinte del siglo $X V^{71}$. En esa década y la siguiente viven en Ourense los hermanos Pedro y Juan González Cuadrado, de los cuales el segundo es en

\footnotetext{
${ }^{65}$ Losada Meléndez, Libros de notas de Juan de Ramuín..., págs. 451, 546 y 643.

${ }^{66}$ López CARreira, Padróns de Ourense..., págs. 152, 169, 177, 195, 214, 227, 246, 250, 264, 273, 282 y 294. Fuera de estas menciones aparace en 1490 como testigo en un arrendamiento (Anselmo LÓPEZ CARreira, Libro de protocolos de Xoán García, notario de Ourense (ano 1490), Santiago de Compostela, Instituto de Estudios Gallegos Padre Sarmiento, 2007 (Monografías de Cuadernos de Estudios Gallegos, 7), pág. 35).

${ }^{67}$ Otero Piñeyro Maseda, Colección diplomática do mosteiro cisterciense..., pág. 505.

${ }^{68}$ López CARreira, Padróns de Ourense..., págs. 106, 128, 131, 147, 152-154, 162, 170, 178, 187, 196, $216,235,247,256,266,274$ y 284.

${ }^{69}$ El primero estaría constituido por quienes pagan 30 — Pedro y Juan González — 25 —Mariña Anes y 20 -Afonso de Córdoba; Afonso, jenro de Diego Fernandes; Fernando Ferro, Mosé Albeitar, Jaco Vello y Juan Patiño-, siendo nueve las personas que pagan 18 maravedíes, incluyendo a Bravo (LÓPEZ CArreira, Padróns de Ourense..., págs. 106-108).

70 Otero Piñeyro Maseda, Colección diplomática do mosteiro cisterciense..., pág. 427 (doc. núm. 3066).

${ }^{71}$ López Carreira, A cidade de Ourense..., págs. 587 y 591.
} 
1435 Joan Coadrado o Vello ${ }^{72}$. En la generación siguiente son dos los zapateros Cuadrado: Rodrigo y Juan Cuadrado ${ }^{73}$, hijos de uno de los dos anteriores, y que vivían, ambos, en la rúa da Barreira ${ }^{74}$. Juan casó, al parecer, dos veces, con Mayor Fernández y con Mayor González; con ambas aforó viñas al cabildo en A Carballeira en 1473, con la primera, y 1483, con la segunda ${ }^{75}$. Este último año, y también con su mujer, aforaba a los canónigos unas casas en la rúa da Fontaíña. ${ }^{76}$

Hijo de uno de los dos matrimonios sería el Juan González Cuadrado o Mozo que en 1490 está casado con María Pérez de Casasoá. A diferencia de su padre, utiliza el González de su abuelo o tío abuelo -aunque podría derivar de su madre, de serlo Mayor González-, si bien habitualmente prescinde de él ${ }^{77}$. Desde 1490 consta que vive en la rúa da Barreira, en la que lo hace también Joan Cadrado o Vello hasta $1504^{78}$. De uno de los dos es criado un tal Gonzalo, que vive asimismo en A Barreira en $1497^{79}$.

Una mención también para el platero Juan Pereiras que aparece como testigo de la compra en Calvelo de 1490. Su profesión y su apellido ${ }^{80}$ lo llevan a relacionarlo con Mayor Pereiras, mujer del también platero Pedro Arias, con lo que sería probablemente primo del canónigo Juan Arias y sus hermanas. De los distintos Pereiras, o Pereira, que se documentan en el Ourense de finales del XV sería el que aparece viviendo en la rúa do Vilar ${ }^{81}$ en los años ochenta, tras lo que pasaría a la del Campo o Tendas - el Juan Prateyro que cotiza en esa zona en $1487^{82}$ - pasando a la das Chousas entre 1488 y $1491^{83}$, año en que desaparece de la ciudad para volver a ella, aunque sólo por ese año, en 1495 en la rúa da Barreira ${ }^{84}$. Sería hermano de Alfonso Pereiras que, a diferencia de él,

\footnotetext{
${ }^{72}$ LÓPEz CARreira, Fragmentos de notarios..., pág. 313

${ }^{73}$ López Carreira, A cidade de Ourense..., págs. 597, 599 y 601; Fragmentos de notarios..., págs. 106, 128, 148, 172, 173, 182; Padróns de Ourense..., págs. 63; Ferro Couselo, A vida e a fala..., págs. 536 y 595 .

74 López Carreira, Padróns de Ourense..., págs. 58-59, 75, 169 y 196.

75 Losada Meléndez, Libros de notas de Juan de Ramuín..., págs. 175-176 y 264-265.

${ }^{76}$ Losada MelÉndez, Libros de notas de Juan de Ramuín..., págs. 266-267.

77 Aparte de la compra que hace en Calvelo (doc. núm. 2), como Joan Gonçalves Cadrado o Moço aparece solamente como testigo en 1490 (LóPEZ CARREIRA, Libro de protocolos de Xoán García..., pág. 28). Que, como he comentado, en la documentación consultada el que debe ser su padre no utilice nunca el González permite suponer que es o Mozo el Juan Gonçalues Cadrado que aparece, también como testigo, en abril de 1484 (Ferro Couselo, $A$ vida e a fala ..., pág. 391).

${ }^{78}$ López CARreira, Padróns de Ourense..., págs. 177, 194, 214, 226, 245, 264, 273, 281-282 y 294.

79 López Carreira, Padróns de Ourense..., pág. 263.

${ }^{80}$ Que se confirman, aparte de en esta venta de Calvelo, al aparecer Juan Pereira, prateiro y vecino de Ourense en 1489 y 1490 como testigo en un foro y una compraventa (LosADA MELÉnDEZ, Libros de notas de Juan de Ramuín..., pág. 522, y LóPez CARReIRA, Libro de protocolos de Xoán García..., págs. 57 y 60).

${ }^{81}$ López Carreira, Padróns de Ourense..., págs. 100, 109, 127.

${ }^{82}$ López Carreira, Padróns de Ourense..., pág. 160.

${ }^{83}$ López Carreira, Padróns de Ourense..., págs. 168, 175, 184.

${ }^{84}$ López CARreira, Padróns de Ourense..., pág. 233.
} 
reside siempre, entre 1480 y 1493, en la rúa do Vilar y que fue alcalde de la Santa Hermandad $^{85}$.

Así pues, en el siglo XV Casasoá está en manos de una familia indudablemente burguesa que, si no forma parte de la capa más alta de la ciudad de Ourense, está inmediatamente tras ella. Si bien ninguno de sus miembros alcanza el regimiento, uno entra en la institución eclesiástica más poderosa de la urbe, la catedral. Tanto Gonzalo de Sarria como el platero Pedro Arias se moverían en un ambiente próximo a la hidalguía, para cuya consecución no cabe duda de que la posesión de un coto señorial como Casasoá, no era baladí para ascender en la escala social, pues pueden presentarse como señores de vasallos, por pocos que fueran estos. Las alianzas matrimoniales se establecen con gente de la misma condición: dos de las hijas del platero se casan con recién llegados a la ciudad que, con seguridad el hijo del notario, menos clara la del portugués, tenían una desahogada posición económica que, con sus bodas, pretendían asegurar e incrementar gracias a las relaciones que le ofrecían sus mujeres. El tercero, el Cuadrado, provenía de una familia de zapateros de la cual una de sus ramas se habría enriquecido lo suficiente como para optar a la mano de la hermana de un canónigo. Así pues, la familia señorial de Casasoá se enmarca en el conjunto de patricios aurienses que, como ha mostrado Anselmo López Carreira, rozan la hidalguía, todavía abierta a integrar en ella a gentes procedentes de la capa más alta - y rica- de la sociedad urbana ${ }^{86}$.

\section{ConClusión}

Así pues, Casasoá se conforma en coto muy probablemente en el siglo XIII, tal vez bajo el manto del monasterio de Ribas de Sil pero, en principio, a favor de una de las familias más poderosas del momento en la tierra de Limia, los Ambía. Estos pueden haberlo cedido a un caballero o escudero de menor importancia, o haberlo vendido en algún momento antes de principios del siglo XV, cuando ha caído ya en manos de gentes cuyo interés está centralizado en la ciudad de Ourense, donde residen. En ese sentido, y sin minusvalorar las rentas que los dueños del coto puedan sacar de éste, no cabe duda de que es mucho más importante el prestigio social que ofrece el ser señor de vasallos, pues muy posiblemente muchos hidalgos no lo eran a pesar de su alcurnia.

Pousa, coto y señorío nacen en el siglo XIII para mantenerse como tales durante todo el Antiguo Régimen, pues a mediados del XVIII Casasoá sigue siendo jurisdicción independiente que, como trescientos años antes, está en manos de

\footnotetext{
${ }^{85}$ López Carreira, Padróns de Ourense..., págs. 100, 109, 127, 168, 176, 185, 194, 213 y 225.

${ }^{86}$ López Carreira, A cidade de Ourense..., págs. 334-338.
} 
un vecino de la ciudad de Ourense. Heredero de la pousa es el pazo, que nada conserva de sus tiempos medievales salvo, probablemente el lugar, pues será completamente reedificado e finales del XVIII o ya en el XIX ${ }^{87}$.

\section{COLECCIÓN DOCUMENTAL}

Se incluyen a continuación los tres pergaminos existentes en el Archivo de la Casa de Casasoá. Para su transcripción se han utilizado las normas del GMH, disponibles en $<$ http://gmh.consellodacultura.gal/proxecto/normas/>.

1454, agosto, 11. Ourense.

Gonzalo de Sarria y su mujer, Inés Alfonso, vecinos de Ourense, entregan al platero Pedro Arias y a su mujer, Mayor Pereira, vecinos de la misma ciudad, la pousa de Casasoá con sus lugares asociados así como el señorío sobre todo ello; la entrega se realiza por no poder el matrimonio donante hacer frente a la deuda que tenía con Pedro Arias y Mayor Pereira.

A. OUREnSE, Archivo de la Casa de Casasoá, perg., orig., gallego, letra cortesana, $370 \mathrm{x}$ $250 \mathrm{~mm}$. Al dorso, letra humanística: «Donación echa del lugar de Casasoa a fabor de Pedro Ares por Gonzalo Sarrea. Año de 1454».

Sabean quantos esta carta et publico instrumento viren et oyren como nos, Gonçalo de Sarrea et Eynes Afonso, miña muller, vezinos et moradores ena çibdade d'Ourens, de liçençia hũ do outro e outro do outro, por esta presente carta, por $\mid$ nos et por toda nosa voz, outorgamos e conosçemos que deuemos e avemos de dar e pagar, renunçiando á ley de duobus rerum deuendi, con todas suas clausolas, a vos, Pedro Ares, prateiro, que soodes presente, outrosi vezino e mo| ${ }^{3}$ rador ena dita çivdade, e a Mayor Pereira, vosa muller, que he absente, grande contia de marabedis que nos avedes prestado, a qual dita contia de marabedies vos, os ditos Pedro Ares e Mayor Pereira, vosa muller, destes e prestastes a nos, os ditos Gonçalo | de Sarrea e Eynes Afonso, mina muller, en tenpo e sazon que nos fazian moyto mester, e espeçialmente para noso manteemento e sustentamento

\footnotetext{
${ }^{87}$ María Teresa Rivera lo incluye entre los pazos orensanos del XVIII (María Teresa RivERA RodRíGUEZ, Los pazos orensanos. Arquitectura del siglo XVIII en la provincia de Orense, La Coruña, Caja de Ahorros Provincial de Orense, 1981, págs. 241-242), si bien a mediados de este siglo el catastro de Ensenada, en el interrogatorio correspondiente al coto de Casasoá, realizado en 1752, se especifica que no ai casa de campo ni alquería alguna, teniendo el lugar quarenta y siete casas hauitadas y habitables, todas en una barriada ... y ai asimismo vn formal de casa arruinado por desidia del dueño (MINISTERIO DE CULTURA Y DEPORTE, Portal de Archivos Españoles (PARES) [en línea], disponible en <http://pares.mcu.es/Catastro> [Consulta: 14/04/2020]).
} 
de nosa vida e honrra e estado, e para reparar nosa fazenda; e outrosi conoçemos que nos avedes feytas | moytas e moy bõas obras que redondaron moyto en noso proueyto; e por quanto nos non teemos guisado de uos dar e pagar todos los ditos marabedies, por ende nos, de nosas propias voontades e sen outro cõostrengemento algun, en emenda $\left.\right|^{6}$ e satisfaçon de todo elo, vos damos e outorgamos e poemos e traspasamos en vos, o dito Pedro Ares, que soodes presente, e ena dita Mayor Pereira, vosa muller, absente, e en todas vosas vozes, segundo e porlo tenpo e vozes, foro e condiçoẽs $\mid$ con que nos perteeçe et perteeçer deue, a nosa pousa e lugares de Casasoaa con todas suas casas e herdades e cortinas e aruores e pascos e montesios e agoas vertentes e correntes e manantes, e foros, seruiços, dereitos e dereituras e cousas | aa dita pousa e lugares perteeçentes e perteeçer deuentes, asi de feito como de dereito, e fazemosvos logo da dita pousa e lugares de Casasoaa voz e señor e verdadeiro poseedor. Damosvos a dita pousa e lugares sobre ditos con $\left.\right|^{9}$ toda a voz e avçon, dereito e jurdiçon tenporal, e justiçia e senorio real, çebil e criminal que a eles avemos e tẽemos.

E renunçiamos sobrelo á ley de innumerata pecunia e á ley e dereito que diz que deuen de seer presentes çertos testemoias a | veer fazer a paga, e que todo ome pode yr contra a confeson que faz en termino de ano e de dous anos e que se poden opõer estas exçepções en çertos anos, renunçiando outrosi e partindo de nos a ley d'engano da mietade do justo preço | ou de mais ou de menos, e a ley e ordenamento real que fala en razon dos ditos enganos e que se poden demandar os taes enganos e reclamar sobre eles en tenpo de quatro anos, e as leys dos enperadores Valediano e Jus $\left.\right|^{12}$ tiniano que falan e traptan en razon da sinpleza das mulleres.

E por esta carta e por la jurdiçon dela vos damos e poemos en jur e en mãao e en posison corporal, real e actoal da dita pousa e lugares sobre ditos de Casa|soaa para que os entredes, poseades e demandedes por vos ou por outro en voso nome, e os defendades e labredes ou façades labrar e reparar, e vsedes e esfrutedes, e façades deles e en eles como de vosa propia cousa | sen outra nosa contradiçon e enbargo, nen doutra persona nen personas algũas. E a mayor abondamento en voso fauor, e non en outra maneira, renunçiamos e demitimos e partimosnos de todo o dereito, voz e avçon que aa dita pousa e $\mid{ }^{15}$ lugares avemos e tẽemos enos senorios propietarios deles. Por vertude da qual demitiçon lles pedimos e rogamos que vos reçeban logo a vos, os ditos Pedro Ares, e a Mayor Pereira, vosa muller, e a vosas vozes | por foreiros das ditas pousa e lugares, ou vos façan deles nouos foros se uos neçesario for.

E prometemos asi por solenpne e firme estipulaçon de aver todo o sobre dito por rato, grato, firme, estable e valedeiro para todo | senpre, e de non yremos nen viinremos nen pasaremos contra elo nen contra parte delo, nenno rebocar nen dizer, propoer nen alegar porlo desatar outra raçon ne $n$ exçepçon algũa, nen 
vos inquietar nen perturbar a dita pousa $\left.\right|^{18}$ e lugares e labradores deles, nen fazer nen dizer por dito nen por feito nen por obra outra cousa algũa en contrario en ninhũ tenpo do mundo nen por algũa maneira; e yndo ou pasando contra elo que vos percamos e pagemos por pena e | postura e interese que sobre nos põemos quinentos floriis d'ouro e de justo peso do regno e cuno d'Aragon; e queremos e outorgamos que tantas quantas vezes contra elo foremos ou pasaremos, ou tentaremos de yr ou pa|sar, que tantas vezes sejamos tiudos a pagar a dita pena; para a qual pagar e todo o sobre dito conprir e agardar obligamos a nos mesmos e a todos nosos bẽes, asi mobles como raizes, avidos e por aver; e por esta $\left.\right|^{21}$ dita carta e por la jurdiçon dela damos poder a qual quer justiça da dita çibdade d'Ourens como doutra qual quer çibdade, vila ou lugar que seja dos regnos e senorios del rey noso señor e a jurdiçon, dos quaes nos | sometemos con todos los ditos nosos bẽes, renunçiando nosa jurdiçon declinatoria e foro para que se por dito ou por feito ou por obra foremos ou pasaremos contra o sobre dito ou contra qual qer parte delo que a vosa |petiçon ou querela nos façan todo o sobre dito tẽer e conprir, e demais que entren e tomen a tantos dos ditos nosos bẽes onde quer e en qual quer lugar que foren achados, asi en eclesiastico como en seglar, e os vendan $\left.\right|^{24}$ ou façan logo vender en almoneda ou fóra dela a bõo varato ou a mãao sen pregon e sen aleylon e sen os prazos e terminos do dereito, e de alg[un] o deles, e dos marabedies que por eles deren de conpra | que entregen e façan pago a vos, os ditos Pedro Ares e vosa muller, dos ditos quinentos floriis d'ouro de pena, se en ela ouueremos caydo e encorrido, e de todas las custas, dapnos, perdas e menoscabos que se vos | recleçeren por aver e cobrar os ditos bẽes de nos ben asi e tan conpridamente como se todo ouvese pasado por defenetiva sentença dada por conpetente juiz de noso foro e a dita sentença por nos fose consentida ${ }^{27}$ e pasada en cousa judgada; a qual dita pena paga ou non que esta carta e todo ho en ela contiudo que seja e fique firme e valla; sobre lo qual renunçiamos, quitamos e partimos de nos e de todas las ditas nosas | vozes ajuda e fauor a pedir benefiçio de restituyçon in integrum e a todo dereito deuino e vmano e estatutos e ordenamentos novos e vellos, rayãas ou inperiãas, e a todas leys goticas e romanas | e outras quaes quer leis e dereitos que nos en esta parte poderian ajudar, e sometemosnos a todas las outras leys e dereitos que nos en esta parte poderian contrariar, e a toda excepçon e defenson de feito $\left.\right|^{30}$ et de dereito, que nunca ende digamos nen fagamos o contrario de todo o suso dito, e fazendo o contrario en algũa parte ou en todo que nos non valla. E outrosi renunçiamos a pedir traslado desta carta e a demandar en | escripto e termino de abogado, e a todas dilações, defensões dilatorias, declinatorias e perentorias, e a todas ferias e bõas razões e alegações en contrario do que dito he ou de parte delo posan | seer datas e alegadas que non vallan nen sejan reçebidas por nos nen por outro en juizo nen fóra del posto que dereito seja, renunçiando outrosi e quitando enos $[$ sic $]$ e das ditas nosas vozes a ley e dereito en que $\left.\right|^{33}$ diz que gẽeral renunçiaçon 
non deue valer; sobre lo qual vos outorgamos hũa carta e contrapto o mais forte e firme que poder seer notado con conselo de letrados.

E eu, o dito Pedro Ares, que sõo presente, | por min e porla dita Mayor Pereira, miña muller, absente, e porlas ditas nosas vozes, asi reçebo de uos, o dito Gonçaluo de Sarrea e Eynes Afonso, vosa muller, a dita pousa e lugares de Casasoaa segundo | e por la via, foro e condições que vos perteeçen e nos lo dades e en nos traspasades, e para conpriremos d'aqui endeante as ditas condições do dito foro das ditas pousa e lugares segundo vos erades obli|gados obligo a elo a todos meus bẽes e da dita miña muller.

Feita a carta ena dita çibdade d'Ourens, honze dias do mes d'agosto, ano do nasçemento de noso señor Ihesu Christo de mill e quatroçentos e ${ }^{36}$ çinqvoenta [sic] e quatro anos.

Testemoyas que foron presentes: Afonso de Sant Lourenço e Johan d'Aluan, mercadores, e Roy Gomez, barbeiro, veciños e moradores ena dita çibdade d'Ourens.

E eu, Diego Diaz, escripuano, | del rey, noso señor, e seu notario publico ena sua corte e en todos los seus regnos e señorios e notario publico ena dita çibdade d'Ourens porlo obispo e porla iglesia desse lugar, | a esto que dito he con as ditas testemoias presente foy e o escripuy e aqui meu nome e signo fyz en testemoyo de verdade, que tal he:

${ }^{39}[$ Signum $]$ Diego Diaz, notario [Rubricado $]$

1490, xullo, 7. Ourense.

Álvaro Calvelo, morador en Santa Mariña do Monte, vende a Juan González Cuadrado «O Mozo» y a su mujer, María Pérez, vecinos de Ourense, la mitad de su lugar de Calvelo, feligresía de Santiago de Zorelle, en el cual vive Gonzalo de Calvelo, por ciento dos reales de plata.

A. OURENSE, Archivo de la Casa de Casasoá, perg., orig., gallego, letra cortesana, 258 x $400 \mathrm{~mm}$. Cosidos, dos folios en papel en los cuales, con letra humanística del siglo XVIII o XIX, se transcribe el documento, traducido al castellano. Al dorso, letra humanística: «Benta de un pedazo de tierras del lugar de Caluelo». Al dorso, letra humanística: «Venta de la metad del lugar de Calbelo por Albaro Calbelo a fabor de Juan Gonzalez Cadrado. Año de 1490».

Sepant quantos esta carta de venda vyren como eu, Aluaro Caluelo, morador en Santa Mariña do Monte, que | soo presente, outorgo e conosco que non seendo costrenido por força nin enduzido por engano nin primia $\left.\right|^{3}$ alguna, mais de miña propia, libre e expontania vontade, vendo fyrmemente e dou por 
juro de here|dade, de dizimo a Deus, para senpre jamais, a vos, Juan Gonçaluez Cadrado, o Moço, que estades presente, | e a vosa muller, Maria Perez, que he absente, vezinos da çibdad d'Ourense, e a todas vosas vozes $\left.\right|^{6}$ e herdeyros para senpre, asy generales como particulares, hes a saber que vos vendo a meetade en|tregamente do lugar do dezimo a Deus que esta syto en Caluelo, freygrisia de Santiago de Çorelle, en que mora Gon|çaluo de Caluelo, con a meetade das casas, pardineyros, herdades e arbores e cortinas e castiñeyros e prados e la| $\left.\right|^{9}$ meyros a el perteesçentes, con todas suas entradas e saidas, jures, dereitos e perteesças, e con seus lymites | e agoas correntes e vertentes e manantes, perteesçentes e perteesçer deventes en qualquer maneyra aa | dita meetade do dito lugar, por preçio e contia de çiento e dous reales de plata que de vos ey resçebidos en rea $\left.\right|^{12}$ les de plata, e pasaron de voso poder ao meu realmente e con efeuto, sobre que renunçio a toda excepçion de $\mid$ non dezer delo o contrario e á ley que diz que a paga deue seer feyta en presençia de notario e testigos, e sy | mays valer de conpra a dita meetade do dito lugar e herdades e arbores e castineyros e cortynas e lameyros e pra $\mid{ }^{15}$ dos e casarellos e cousas a elo perteesçentes que a dita contia que asi por elo me destes e pagastes e eu de vos re|çebi, segund dito he, douvos de mais en pura donaçion valedeyra para senpre segund que donaçion mellor e mais | conplidamente pode e deue seer dada entre bybos e de dereito mays deue valer, por moytas e bõas ovras que de $\left.\right|^{18}$ vos ey reçebidas e entendo resçeber en adiante e porque delo me plaze e he asy miña vontade.

E logo todo jur, | dereito, senorio, posesyon, propiedade, voz et abçion que eu ey e teño e poderia aver e tẽer aa dita meetade do dito | lugar e casas e cousas suso ditas aa dita meetade do dito lugar perteesçentes todo o quito, parto e amobo ${ }^{21}$ de min e de meus herdeyros e o poño, dou, çedo e traspaso en vos, o dito Juan Gonçaluez Cadrado, e en vosa muller e | vosos herdeyros para senpre jamays, e por esta presente carta vos poño e apodero logo ena teença e corporal po|sesion da dita meetade do dito lugar e tarreos e herdades e casas e casarellos e arbores e castiñeyros e prados $2^{24}$ e lameyros e cousas a elas deuidas e perteesçentes para que façades e mandedes fazer delas e en elas d'aqui endiante | toda vosa libre vontade e o que vos aprouver como de vosa cousa propia, e a posades entrar, tomar e resçebir por vo|sa propia abtoridade syn liçençia de juez nin de alcalde nin de outro ofiçial algund do dereyto para elo seer chamado, ${ }^{27} \mathrm{e}$ prometo e outorgo de non yr nin biir nin pasar contra elo por min nin por outro en juizo nin fóra del en ningund tenpo nin | por alguna manera, nin alegar ey contra elo engano nin outra razon alguna en contrario do sobre dito, ante que vos | farey esta dita venda sãa e de paz, e vos defender ey con ela a dereyto so pena do dobre da dita contia, que vos $\left.\right|^{30}$ dea e pague de pena, postura e ynterese sy o asy non conprir e agoardar; e a dita pena pagada ou non esta carta e todo o en ella contiudo fique firme e valla para senpre; para o qual todo asy tẽer, conprir e 
agoardar e vos lo fazer sãa e de paz | e non yr contra elo obligovos a elo todos meus bẽes, mobeles e raizes, e de meus herdeyros, sobre lo qual todo renun $\left.\right|^{33}$ çio; e parto de min a todas las leys e dereitos, escriptos e non escriptos, asy canonicos como çebiis, e asy en general como $\mid$ en espiçial, e a toda ley de engano e todo benefiçio de restytuyçion yn yntegrum e a todas las outras leys e dereitos que | falan en razon das cousas que son vendidas por mays ou por menos do justo preçio, e todas las outras boas ${ }^{36}$ razõos, dereitos e defensõos que en contrario do sobre dito sejan ou seer posan en qual quer maneyra que me non | vallan en juizio nin fóra del posto que dereito seja; e espeçialmente renunçio á ley do dereito que dize que general renunçiaçion $\mid$ non valla.

E porque esto seja çerto e firme e non veña en dubda outorgueyvos delo esta carta ante o notario publico $\left.\right|^{39} \mathrm{e}$ testigos yuso escriptos forte e firme tal qual por letrado, ao qual roguey que a escriuise ou fezese escriuir | e a synase de seu syño.

E eu, o dito Juan Gonçaluez Cadrado, que sõo presente, para min e para a dita miña muller e nosos $\mid$ herdeyros, asy o resçebo.

Que foy feyta e outorgada ena çibdade d'Ourense, a sete dias do mes de jullio, ano do $\left.\right|^{42}$ nasçemento de noso señor Ihesu Christo de mill e quatroçentos e noventa anos.

Estando a elo presentes por testigos: | Juan Pereyras, prateyro, e Aluaro Gonçaluez de Çerreda, e Garçia Nunez, escriuano, veziños da dita çibdade, e outros.

E yo, Juan Garçia, | escriuano de camara del rey nuestro señor e su notario publico en la su corte e en todos los sus regnos e señorios, e notario publico de la çibdad $\left.\right|^{45}$ e obispado de Orense por el señor obispo e ygllesia dese lugar, e otrosy notario del conçejo de la dicha çibdad, a todo lo que dicho es en vno con los dichos testigos fui | presente al otorgamiento de la dicha carta e la fize escriuir e por ende puse aqui mi nonbre e signo acostumbrado en testimonio de verdad, que tal es.

Juan Garçia, notario [rubricado].

1498, julio, 17. Ourense.

El canónigo auriense Juan Arias y sus cuñados Alfonso González Portugués, Juan Cuadrado «O Mozo» y Juan Bravo, todos vecinos de la ciudad de Ourense, para evitar problemas entre ellos, se reparten las rentas del lugar de Casasoá, feligresía de Santiago de Zorelle: de la carne, sea de cerdo sea de cualquier otra especie, que se reciba como renta la mitad quedará para el canónigo, repartiéndose la otra mitad en tercios entre los tres cuñados; de la renta del pan 
el canónigo recibirá, en primer lugar, dos fanegas, sacadas las cuales el resto se repartirá en cuartos iguales entre los cuatro beneficiados; el resto de las rentas se repartirán asimismo en cuartos iguales; de la misma manera, por cuartos, han de prorratearse los pagos a los que estén obligados canónigo y cuñados así como los gastos que puedan derivarse de cualquier pleito o problema que afecte al conjunto de bienes.

A. Ourense, Archivo de la Casa de Casasoá, perg., orig., gallego, letra cortesana, 310 x $468 \mathrm{~mm}$. Borrón en la esquina superior izquierda que impide la lectura del texto incial de las líneas 2 a 6; tinta desvaída en varios lugares del documento, perdiéndose el texto correspondiente. Al dorso, letra humanística: «Año de 1498». Al dorso, letra humanística: «Es del lugar de Casasoa». Al dorso, letra humanística: «Concordia [...] el canonigo Juan Ares [...] Quadrado [...] Portugues e Juan [...] del lugar de Casaso[...]».

Sepan quantos esta carta de contrato conçerto e igoala viren como eu, Iohan Ares, canonigo na igllesia d'Ourense e veziño da çibdade de Ourense | [...] de meus erdeiros, e uos, Afonso Gonçalez Portugues, e Johan Quadrado, o Moço, e Ioan Bravo, veciños $\left.\right|^{3}[\ldots]$ Ourense, que somos presentes, da outra parte, por nos e en nome de nosas mulleres, yrmãas de vos, o dito $\mid[\ldots]$ por las quães obligamos nuestras personas e vienes que elas veran por firme, estable e valedeiro [...] [...] e contenido outorgamos e conosçemos por esta presenta carta que por razon [...] nosos heredeiros $\left.[\ldots]\right|^{6}[\ldots]$ question e devate sobre o lugar [...] del que jaz e esta sito [...] frey|[ge]sia de Santiago de Çorelle de terra de Raveenda, e por viíremos a võoa paz e concordia e nos quitar e partir e apreitar e deva[...] | expensas, odios e malquerenças que entre nos e nosos eredeiros poderian recresçer sobre o dito lugar, e por viíremos a võoa paz e concor $\left.\right|^{9}$ dia, e por el devedo que era[...] raçones de nosas propoas e libres voontades, sin premia nin costregimento algun nos conçer|tamos e ygoalamos en esta maneira:

Que eu, o dito Iohan Ares, canonigo, leve e aja para min e para meus erdeiros aa meetade de toda a $\mid$ carne, asi de porco como de outra qual quer que seja, que render e se ouver de pagar de renda en cada vn ano do dito lugar de Casasoaa, e a outra $\left.\right|^{12}$ meetade que a partamos e levemos e ajamos nos, los ditos Afonso Gonçalez Portugues e Iohan Cadrado, o Moço, e Iohan Brauo, para nos | e para nosos herdeiros yrmãamente, cada vn sua terçia parte.

E mais que de todo o pan que render e se ouver de dar e pagar de renda en | cada vn ano do dito lugar de Casasoaa e por el que leve e aja eu, o dito Ioan Ares, canonigo, duas fanegas de melloria para min e para meus $\left.\right|^{15}$ eredeiros, e mais todo o outro pan que render e se ouver de dar e pagar de renta en cada vn ano eno dito lugar que o partamos e levemos | e ajamos todos quatro yrmãamente, e cada vn leve sua parte del; e eu, o dito Ioan Ares, leve de mais e melloria as ditas duas fanegas de pan. 
E | todolo que mais render o dito lugar que o partamos todos quatro ermanamente según dito he, e mais outras rendas que en el solian de dar.

${ }^{18} \mathrm{E}$ que seamos obrigados de pagar los foros e rendas ao señorio que eno dito lugar ouver de aver en cada vn ano, de maneira que o dito lugar se non | perca por mingoa de los pagar.

E mais que si algun preito se nos mover contra el ou se nos recresçer con outras algunas personas que nos $\mid$ e nosos erdeiros, todos juntamente, sejamos obrigados de o defender por justiça a nosa custa e mision de nos e de cada vn de nos $\left.\right|^{21}$ en quatro partes. E mais que si algun de nos ouver de vender ou enpeñar a sua parte do dito lugar ou nosos eredeiros que o non posa $\mid$ quitar e o venda e dea por lo tanto aos outros y [...] se o vender de outra maneira que non valla nin posa venderla [...]|narlo. E que si alguna sentençia ou sentençias, mandamento ou mandamientos, nos ou alguns de nos [...] emos vnos contra los otros ${ }^{24} \mathrm{q} u e-$ remos e es nuestra voluntad que todos gozemos del titulo foro e [der] echo del dicho lugar todos quatro yrmãamente e nosos here|deiros, e si algun de nos ou as ditas uosas mulleres de nos, os ditos Iohan Brauo e Iohan Quadrado, o Moço, e Afonso Gonça|lez Portugues, teemos mellor dereito vnos que los outros ou os outros que os outros que todos quatro yrmãamente e nosos ere $\mid{ }^{27}$ deiros gozemos del para que cada vn leve a sua parte do que render o dito lugar sigun [sic] dito he e da maneyra que dito he, e si | nesçesario es lo renunçiamos e traspasamos los vnos en los outros e los otros en los otros para que o ajamos e teñamos $\mid$ e gozemos segun e da maneira que dita he.

E desde ahora nos partymos e apartamos de quales quier preitos, questiões, demandas, ${ }^{30}$ auçiones que tenamos postos e movidos vnos contra los outros e os outros contra os outros, e queremos que nos non vallan [...] delo nos | posamos aproveitar, saluo deste dito conçerto, igoala e asento que aqui por nos he feito e outorgado, e prometemos e outor|gamos de non yr nin pasar contra elo nin contra ninguna parte delo aora nin en ningun tenpo nin por alguna maneyra, e si $\left.\right|^{33}$ contra elo foremos ou pasaremos nos en cada vn de nos ou nosos eredeiros que non valla nin sejamos sobre elo oi|dos nin resçeuidos por non nin outros en noso nome en juizio nin fóra del, e que paguemos de pena, postura e ynterese | a parte que contra el for e pasar dez mill marabedis pares de brancas, a meetade para a parte agoardante e a outra meetade | para la justiça que o exsecutare, para lo qual obligamos a nos e a todos nosos vẽes e de nosos herdeiros, mobiles e raizes, ${ }^{36}$ avidos e por aver, para o qual tẽer e goardar e conprir en todo e por todo por la presente damos poder conplido todas | e quaes quer justiças, asi heclesiasticas como seglares, de todas las çibdades, villas e logares deste reyno de Galizia, e | a otras quales quier justiças ante quen esta carta paresçer e for presentada e pedido de la conprimento de justiça para que nos ${ }^{39}$ conpelan e apremeyean, e a cada vn de nos, por todos los rigores e remedios do dereito, e nos fagan terre, conprir 
e | agoardar todo lo en ela contenido, e esecuten a dita pena si en ela caeremos e ya[... ]emos en nosos bees e de $\mid$ nosos eredeiros e en caso que a dita pena seja paga ou non vna vez e ou [...] todavia queremos e outorgamos que $\left.\right|^{42}$ este dito contrato, conçerto e igoala seja firme e valla, e as cousas en el contenidas, para senpre, sobre que renun|çiamos a toda lei de agaño e a todo venefiçio de restituiçon in integrum e a todas las outras leis e dereytos | escritos e non escritos, canonicus e çeviis, e espeçialmente renunçiamos a ley e dereyto que diz que general renun|çiaçom non valla.

E outrosi eu, o dito Ioan Ares, canonigo, renunçio otro qual quer remedio e exseiçon que en contra $\mid{ }^{45}$ rio desto posa dezer e alegar por razon de miña clerezia, porque quero que me non valla, saluo el conprimento | deste dito contrato.

En fe do qual nos, las ditas partes, outorgamos ende delo esta carta de contrato, conçerto e | igoala da maneira que dita es ante o presente notario e testigos de yuso escritos.

Que foi feita e outorgada ena çib|dade d'Ourense, a dez e sete dias do mes de julio, ano do nasçemento do noso senor Ihesu Christo de mill e $\left.\right|^{48}$ quatroçentos e noventa e oito anos.

Estando presentes por testigos: Joan Pereyra, prateyro, Gomez de Ramoyn, | tondidor, Gonçalo de Leon, xastre, veziños da dita çibdade.

Va sobre raido o diz «quatroçentos».

E yo, Roy | Gonçaluez de Maçeredo, escriuano de camara del rei e de la reina, nuestros señores, e seu notario publico en la sua corte e en $\left.\right|^{51}$ todos los seus reynos e señorios, e notario de la çibdad e obispado e vno de los ocho de numero de la $\mid$ dicha çibdad por el señor obispo e iglesia dese logar, que al otorgamiento desta dita carta de conçerto e igliuala [sic] en vno $\mid$ con los dichos testigos presente fvy e aqui por mano de otro escrevyr lo fiz, e por ende puje aqui este mi non $\left.\right|^{54}$ bre e syno acostumado en testimonio de verdad, que tal he.

| [Signum] Roy Gonçaluez, notario [rubricado].

\section{ÍNDICE TOPONÍMICO}

ARAGÓN: antiguo reino que se extendía aproximadamente por la actual C. A. del mismo nombre: 1 .

Caluelo (2): vide Calvelo.

CAlvelo: lugar de la fg. ${ }^{a}$ de Santiago de Zorelle, ayt. ${ }^{\circ}$ de Maceda, prov. ${ }^{a}$ de Ourense: 2.

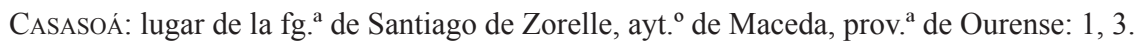

Casasoaa (1, 3): vide Casasoá.

GALICIA: antiguo reino que se extendía aproximadamente por la actual C. A. del mismo nombre: 3 . 
Galizia (3): vide Galicia.

León (3): vide León, Santa Baia de.

LeÓN, SANTA BAIA DE: fg. ${ }^{a}$ del ayt. ${ }^{o}$ de Vilamarín, prov. ${ }^{a}$ de Ourense: 3.

Ourens (1): vide Ourense.

OURENSE: ciudad cabeza del ayt. ${ }^{\circ}$ y prov. $^{\text {a }}$ de su nombre: $1,2,3$.

RABEDA, tierra de: antigua demarcación que se extendía, en todo o en parteo, por los actuales términos municipales de San Cibrao das Viñas, Taboadela, Paderne de Allariz y Maceda: 3.

RAmuín: lugar de la fg. ${ }^{a}$ de Santa María de Viñoás, ayt ${ }^{\circ}$ de Nogueira de Ramuín, prov. ${ }^{a}$ de Ourense: 3 .

Raveenda (3): vide Rabeda.

SAnta Mariña Do Monte: lugar y fg. ${ }^{a}$ del ayt ${ }^{\circ}$ y prov. ${ }^{a}$ de Ourense: 2.

Santiago de Çorelle $(2,3)$ : vide Zorelle, Santiago de.

Sarrea (1): vide Sarria.

SARRIA: villa cabeza del ayt. ${ }^{\circ}$ de su nombre, prov. ${ }^{a}$ de Lugo: 1.

Zorelle, Santiago de: fg. ${ }^{a}$ del ayt. ${ }^{\circ}$ de Maceda, prov. ${ }^{a}$ de Ourense: $2,3$.

\section{ÍNDICE ONOMÁSTICO}

Afonso de San Lourenzo, mercader, vecino de Ourense: 1.

Afonso González Portugués, vecino de Ourense (1498): 3.

Aluaro (2): vide Álvaro.

Álvaro Calvelo, morador en Santa Mariña do Monte: 2.

Álvaro González de Cerreda, vecino de Ourense: 2.

Diego Díaz, notario de Ourense: 1.

Eynes (1): vide Inés.

García Nunes, escribano, vecino de Ourense: 2.

Gómez de Ramuín, tundidor, vecino de Ourense: 3.

Gonçalo / Gonçaluo (1, 2): vide Gonzalo.

Gonzalo de Calvelo, morador en Calvelo: 2.

Gonzalo de León, xastre, vecino de Ourense: 3.

Gonzalo de Sarria, marido de Inés Alfonso, vecino de Ourense (1454): 1.

Inés Afonso, mujer de Gonzalo de Sarria, vecina de Ourense (1454): 1.

Iohan (3) / Johan (1) / Juan (2): vide Xoán. 
María Pérez, muller de Xoán González Cuadrado, o Mozo, vecina de Ourense (1490): 2.

Mayor Pereira, mujer del platero Pedro Ares (1454): 1.

Pedro Ares, platero, marido de Mayor Pereira, vecino de Ourense (1454): 1.

Rodrigo Gómez, barbero, vecino de Ourense: 1.

Rodrigo González de Maceiredo, notario de la ciudad y obispado de Ourense: 3.

Roy (1, 3): vide Rodrigo.

Xoán Ares, canónigo y vecino de Ourense (1498): 3.

Xoán Bravo, vecino de Ourense (1498): 3.

Xoán Cuadrado, o Mozo (3): vide Xoán González Cadrado, o Mozo.

Xoán de Albán, mercader, vecino de Ourense: 1.

Xoán García, notario de la ciudad y obispado de Ourense: 2.

Xoán González Cadrado, o Mozo, marido de María Pérez, vecino de Ourense (1490-98): 2, 3.

Xoán Pereira, platero, vecino de Ourense: 2, 3.

\section{BIBLIOGRAFÍA}

Andrade Cernadas, José Miguel, O Tombo de Celanova, Santiago de Compostela, Consello da Cultura Galega, 1994, 2 tomos.

Bouzas Rosende, Paula, Documentos galegos do mosteiro de Santo Estevo de Ribas de Sil (século XV), Santiago de Compostela, Consello da Cultura Galega, 2016.

Calderón Medina, Inés, Cum Magnatibus regni mei. La nobleza y la monarquía leonesas durante los reinados de Fernando II y Alfonso IX (1157-1230), Madrid, Consejo Superior de Investigaciones Científicas, 2011 (Biblioteca de Historia, 74).

Dono López, Pedro, Colección de documentos en pergamiño do mosteiro de Santa Comba de Naves. Introdución, edición e índices, Tesis doctoral inédita, Santiago de Compostela, Universidade de Santiago de Compostela, 2010.

Duro Peña, Emilio, El monasterio de San Pedro de Rocas y su Colección Documental, Orense, Diputación Provincial, 1972.

Duro Peña, Emilio, "El monasterio de Santa Marina de Asadur”, Archivos Leoneses, 27 (1973), págs. 309-365.

Duro Peña, Emilio, El monasterio de San Esteban de Ribas de Sil, Orense, Diputación Provincial, 1977.

Fernández Fernández, Adolfo, O mosteiro feminino de San Miguel de Bóveda na Idade Media. Estudio histórico e colección documental (séculos XII-XV), Noia, Toxosoutos, 2005 (Trivium, 17).

Ferro Couselo, Jesús, A vida e a fala dos devanceiros: escolma de documentos en galego dos séculos XIII ao XVI, Vigo, Galaxia; Fundación Penzol, 1996 [ed. facs. de la de 1967]. 
Gallego Domínguez, Olga, La organización administrativa territorial de la antigua provincia de Ourense a mediados del siglo XVIII, Ourense, Museo Arqueolóxico Provincial, 1988 (Boletín Auriense, anexo 10).

García Oro, José y Portela Silva, María José, O condado de Monterrei no século XVI. Estudo histórico e colección diplomática, Noia, Grupo Filatélico e Numismático de Noia, 2003.

Gordín Veleiro, Ana María, Minutarios notariais de Rodrigo Afonso, Gonzalo de Baeza e Pedro Sánchez de Baeza (Ourense, siglo XV), Tesis doctoral inédita, Ourense, Universidade de Vigo, 2015.

Gordín Veleiro, Ana María, y Peña Pérez, Luisa de la Ascensión, O mosteiro de Santa María de Xunqueira de Espadanedo nos séculos XII-XVI, Ourense, Deputación de Ourense, 2019.

Iglesias Almeida, Ernesto, "El monasterio de San Pedro de Angoares", Soberosum. Revista de Estudios Museo Municipal de Ponteareas, 1 (1993), págs. 115-131.

López Carreira, Anselmo, Padróns de Ourense no século XV, Santiago de Compostela, Consello da Cultura Galega, 1995.

López Carreira, Anselmo, A cidade de Ourense no século XV. Sociedade urbana na Galicia baixomedieval, Ourense, Deputación Provincial, 1998.

López Carreira, Anselmo, Libro de notas de Álvaro Afonso. Ourense, 1413, Santiago de Compostela, Consello da Cultura Galega, 2005.

López Carreira, Anselmo, Fragmentos de notarios (Ourense, séculos XIV-XVI), Santiago de Compostela, Consello da Cultura Galega, 2007.

López Carreira, Anselmo, Libro de protocolos de Xoán García, notario de Ourense (ano 1490), Santiago de Compostela, Instituto de Estudios Gallegos Padre Sarmiento, CSIC, 2007 (Monografías de Cuadernos de Estudios Gallegos, 7).

López Martínez, Amalia, Minutarios notariales de Estevo Pérez, Tesis doctoral inédita, Ourense, Universidade de Vigo, 2015.

Lorenzo, Ramón, Colección documental do mosteiro de Montederramo, Santiago de Compostela, Consello da Cultura Galega, 2016, 3 tomos.

Losada Meléndez, María José, Libros de notas de Juan de Ramuín (Ourense, siglo XV), Tesis doctoral inédita, Ourense, Universidade de Vigo, 2015.

Lucas Álvarez, Manuel, y Lucas Domínguez, Pedro Pablo, San Pedro de Ramirás. Un monasterio femenino en la Edad Media. Colección diplomática, Santiago de Compostela, Caixa Galicia, 1988.

Marques, José, O cartulário do mosteiro de Fiães, Melgaço, Câmara Municipal de Melgaço, 2016.

Martínez Coello, Antonio, “Santa María de Moreira”, en Damián Yáñez Neira (coord.), Monasticón cisterciense gallego, tomo II, León, Caixavigo e Ourense-Edilesa, 2000, págs. 268-285.

Otero Piñeyro Maseda, Pablo S., Colección documental del Archivo de la Casa de Otero de Quiroga (Siglos XIII-XVIII), Lugo, Diputación provincial, 2007.

Otero Piñeyro Maseda, Pablo S., Colección diplomática do mosteiro cisterciense de Santa María de Oseira (Ourense) 1435-1484, vol. V, Santiago de Compostela, Tórculo Edicións, 2008. 
Otero Piñeyro Maseda, Pablo S., "Apuntes de los Ambía: linaje y parentelas (siglos XIIXVI)", Cuadernos de Estudios Gallegos, 56 (2009), págs. 445-457.

Otero Piñeyro Maseda, Pablo S., “Apuntes genealógicos de una estirpe de escuderos gallegos: los Mosquera (siglo XV)”, en José Antonio García Luján (ed.), Simposio Nobleza y Monarquía. Los linajes nobiliarios en el reino de Granada. Siglos XV-XIX. El linaje Granada Venegas, marqueses de Campotéjar, Huéscar, Asociación Cultural Raigadas, 2010, págs. 207-227.

Pardo de Guevara y Valdés, Eduardo, De linajes, parentelas y grupos de poder. Aportaciones a la historia social de la nobleza bajomedieval gallega, Madrid, Fundación Cultural de la Nobleza Española, 2012.

Pérez Rodríguez, Francisco Javier, "Monjes, poder y política”, en José Miguel Andrade Cernadas (coord.), El protagonismo monástico a través de la Historia, A Coruña, Hércules de Ediciones, 2016, págs. 153-189.

Quiroga Barrio, Gabriel, A casa da Veiguiña: Descrición do fondo documental, Santiago de Compostela, Consellería de Cultura e Turismo; Arquivo Histórico Provincial de Lugo, 2018.

Río Barja, Francisco Javier, Cartografía Xurisdiccional de Galicia no século XVIII, Santiago de Compostela, Consello da Cultura Galega, 1990.

Rivera Rodríguez, María Teresa, Los pazos orensanos. Arquitectura del siglo XVIII en la provincia de Orense, La Coruña, Caja de Ahorros Provincial de Orense, 1981.

Romaní Martínez, Miguel, A colección diplomática do mosteiro cisterciense de San María de Oseira (Ourense) (1025-1310), Santiago de Compostela, Tórculo Edicións, 1989.

Romaní Martínez, Miguel, y Otero Piñeyro Maseda, Pablo S., "Documentación del fondo de Oseira (AHN) relacionada con el monasterio de San Pedro de Vilanova de Dozón (10151295)", Cuadernos de Estudios Gallegos, 116 (2003), págs. 27-77.

Romaní Martínez, Miguel; Otero Piñeyro Maseda, Pablo S., y Garrido, Margarita, Colección diplomática do mosteiro cisterciense de Santa María de Oseira (Ourense), 1400-1435, vol. 4, Santiago de Compostela, Tórculo Edicións, 2003.

Romaní Martínez, Miguel; Portela Silva, María José; Rodríguez Suárez, María Pilar, y Vázquez Bertomeu, Mercedes, Colección diplomática do mosteiro cisterciense de Santa María de Oseira (Ourense), 1310-1399, vol. 3, Santiago de Compostela, Tórculo Edicións, 1993.

Sottomayor-Pizarro, José Agusto, "Os Limas: da Galiza a Giela (séc. XII a XVI)", en Casa Nobre. Um património para o futuro. $2 .{ }^{\circ}$ Congresso Internacional. Actas, Arcos de Valdevez, Municipio de Arcos de Valdevez, 2011, págs. 53-74.

Vaquero Díaz, María Beatriz, “A xestión patrimonial do mosteiro de Celanova na Baixa Idade Media”, Semata, 15 (2003), págs. 223-236.

Vaquero Díaz, María Beatriz, Colección diplomática do mosteiro de San Salvador de Celanova (ss. XIII-XV), Vigo, Concello de Celanova-Universidade de Vigo, 2004.

Vaquero Díaz, María Beatriz, Libro das posesións do Cabido Catedral de Ourense (1453). Edición, transcrición e índices, Vigo, Universidade de Vigo, 2005.

Vaquero Díaz, María Beatriz, y Pérez Rodríguez, Francisco Javier, Colección documental del Archivo de la Catedral de Ourense, I (888-1230), León, Centro de Estudios e Investigación San Isidoro; Caja España de Inversiones; Archivo Histórico Diocesano, 2010 (Colección Fuentes y Estudios de Historia Leonesa, 131). 